\title{
Impact of Forest Fragment on Bird Community at the Bukit Kuantan Rubber Forest Plantation
}

\author{
Radhiah Abdul Kadir ${ }^{1 \varpi}$, Mohd Ikram Mohammad ${ }^{2}$ and Syaizwan ZahmirZulkifli ${ }^{3}$ \\ ${ }^{1}$ Crop Management Unit, Rubber Research Institute Experimental Station Sungai Buloh, Malaysian Rubber Board, 47000 Sungai \\ Buloh, Selangor, Malaysia. \\ ${ }^{2}$ Processing and Sustainability Unit, Rubber Research Institute Experimental Station Sungai Buloh, Malaysian Rubber Board, \\ 47000 Sungai Buloh, Selangor, Malaysia. \\ ${ }^{3}$ Department of Biology, Faculty of Science, Universiti Putra Malaysia, 43400 UPM Serdang, Selangor
}

\begin{abstract}
Realizing the potential of expanding rubber forest plantations in Malaysia and the increasing awareness of biodiversity, the Bukit Kuantan rubber forest plantation portrays its ecofriendly nature through several initiatives such as conservation of natural forest fragment within the plantation landscape. By using birds as an indicator, this work aims for a favourable outcome from conservation of the forest fragment and investigate bird diversity in relation to distance from the forest fragment into the rubber forest plantation area. The number of bird species recorded is high in the forest fragment i.e., 45 species, however, the number steadily declined with distance. Likewise, species diversity is high in the forest fragment, $\mathrm{H}^{\prime}=3.404$ but declined with distance. Fourteen (14) species are exclusively found in the forest fragment. Through the findings, it can be deduced that the presence of forest fragment helps to increase bird diversity in the rubber forest plantation, although continuous research is still required to understand how the presence of forest fragment sustains the biodiversity within a plantation landscape.
\end{abstract}

Keywords: rubber forest plantation, bird fauna, forest fragment, environment friendly plantation.

\section{Introduction}

Concern over the expansion of land area for plantation is growing especially in Southeast Asia (Aratrakorn et al., 2006; Cotter et al., 2009; Aziz et al., 2010; Achondo et al., 2011; Behm et al., 2013; Warren-Thomas et al. 2015). This is largely due to the establishment of plantations that are often associated with a mono-crop system which only allowed a particularcrop species to exist in a single area. From the ecological perspective, such establishment would result in biodiversity-poor ecosystem and species with low conservation status (Aratrakorn et al. 2006). Despite this and without depriving the importance of agriculture, many researchers are still urging that plantations may be fostered into an area that is rich in biodiversity (Norton, 1998; Najera and Simonetti, 2009). Thus, a better understanding of how plantations impact biodiversity is essential for developing environment friendly plantations.

Nonetheless, a mono-crop plantation still has the potentialin harbouring biodiversity into the plantation matrix through certain approaches. Research has identified several approaches that could be integrated with plantation ecosystem such as conservation of forest fragment or riparian buffer zones within the plantation matrix, creating complex vegetation structures, enhancing landscape heterogeneity, and maintaining understory vegetation and mature trees (Azlan et al. 2019; de Matos et al. 2018; Zhang et al. 2017; Najera and Simonetti, 2009). By having a diverse tree and shrubs in term of structure and floristically, scientist believe that it could increase the diversity of an area in term of species density, species abundance and species richness (Perfecto et al., 2004; Najera and Simonetti, 2010; Achondo et al., 2011). These practices could help to shift the poor biodiversity plantations to a less hostile environment. Due to the feasibility, many researchers urge current plantation managers to restructure their plantation management for them to continue their production without eliminating ecological aspects.

* Corresponding author: radhiah@lgm.gov.my 
Optimistically, several publications encouraged forest fragment preservation within the plantation matrix as it helps to maintain a viable population of several fauna species (Achondo et al., 2011; Cotter et al., 2009). Although the existence of forest fragment has some dra wbacks, i.e., increa se forest patch and creating forest edge effect (Jones et al. 2010), researchers have the confidence that forest fragment in plantation area would offer a wide range of habitat suitability for other species to colonize and live, mainly due to diversified physical condition (Dumbrell et al., 2008) and additionalfood sources (Norton, 1998). Murcia (1995) stated that the edge effect of a forest fragment can provide a habitat transition between forest and plantation. Both forest fragment and plantation grounds may serve as corridors that could be accessed by a variety of species, such as birds, which always move from one place to another (Peh et al. 2006). Sometimes, this is crucial for both the diversity and productivity of the plantation. For example, research that was carried out by Chacoff and Aizen (2006) in Argentina found that pollinator-dependent crops heavily rely on the presence of remnant forest as it is the main habitat for most of the pollinating agents.

Although apparently feasible, to date, available reports on plantation management practices that are able to support conservation of biodiversity while maintaining their production and productivity remain scarce (Najera and Simonetti, 2009). Thus, research is still needed to identify conservation strategies that could improve biodiversity within a plantation ecosystem. In light of the growing a wareness of the importance of biodiversity conservation as well as in proposing a rubber forest plantation management system that benefit s both economic and environmental purposes, an investigation was conducted to explore the effectiveness of the presence of forest fragment within rubber forest plantation ecosystem in conserving bird diversity. Birds were chosen as the subject of this study because birds are: 1) a good indicator of species richness, endemism pattern and early signage of environmental changes, 2) easy to sample and identified, 3) sensitive to changes in the habitat conditions, 4) plays an ecological role as predator, prey, pollinator or seed dispersal agent, 5) act as a supporting service role such as pest controlagent and nutrient deposition (Ismail and Syaizwan, 2005; Peh et al., 2006; Achondo et al., 2011; Jamil et al., 2015).

\section{Materials and methods}

\subsection{Study Sites}

The study was conducted at the Malaysian Rubber Board (MRB) Rubber Research Station located in Bukit Kuantan, Pahang, Peninsular Malaysia $\left(3^{\circ} 59^{\prime} 18.3^{\prime} \mathrm{N} 103^{\circ} 14^{\prime} 48.0\right.$ 'E). The locality was formerly a logged forest area before it was converted into a rubber forest plantation that is managed by the MRB. Latex and timber are the main produce of this rubber forest plantation. The rubber forest plantation is managed in a sustainable manner to provide other benefits such as soil, biodiversity and environmental conservation. The Bukit Kuantan rubber forest plantation whilst attempting to incorporate mainstream biodiversity into its plantation management, has three distinctive ecological habita ts comprising of the rubber planting, forest fra gment and wetland a rea. The rubber planting a rea represents the largest land-use with two types of indigenous trees left for conservation purposes i.e., Bayas (Oncosperma horridum) and Nibong trees (Oncosperma tigillaria) that are found scattered in the area. The forest fragment area, also termed as special management zone (SMZ), consists of natural forested areas where land clearing and planting activities are prohibited. Naturally occurring small rivers also lie within this area, while the wetland area, which is termed as working for water (WFW), is essentially a man-made pond.

\subsection{Data Collection}

The bird surveys were carried out using the point count method from February 2015 until March 2016. This method were adopted as it is suited for sampling bird diversity in large areas (Bibby et al., 1992). The bird surveys were conducted along four line transects, each with four sampling points, and were gradually segmented away from the forest fragment area e.g., SMZ $(0 \mathrm{~m}, 300 \mathrm{~m}, 600 \mathrm{~m}, 900 \mathrm{~m})$ with $0 \mathrm{~m}$ indicating the SMZ area, and all of which accounted for a total of 16 sampling points. The observations were conducted at monthly intervals for three consecutive days. The sampling points are shown in Table 1. Observations were carried out using point count observation method following the standards and applications as proposed by Ralph et al. (1995). Observations were made by recording the presence and activities of birds that were either stationary (resting) or mobile (flying) within $50 \mathrm{~m}$ radius of a sampling point (Ralph et al., 1995). Equipment used for the observation include binoculars (Bushnell 8 x 42), camera binoculars (Bushnell 8 x 30), body camera (CanonEOS 70D), lens (Canon 100-400 mm and Tamron 150-600 mm), rangefinder, and Geographical Positioning System (GPS). The birds were observed at two-time intervals, early morning $(0630 \mathrm{~h}-1030 \mathrm{~h})$ and late afternoon $(1530 \mathrm{~h}-1730 \mathrm{~h})$ due to the notion that their movements were considered at maximum during these hours of the day. No observation were recorded during high precipitation and strong winds. Identification and naming of the bird species based on scientific names were conducted according to Davison and Fook (2003) and Davison and Aik (2010) while the bird's localname was retrieved from the Checklist 
of the Birds of Peninsular Malaysia (Blakewell, 2012). Bird feeding guilds were determined mainly from Wong (2012), Nur Munira et al. (2011) and Wielstra et al. (2011).

Table 1 The sampling points and the corresponding geographical positions

\begin{tabular}{llcc}
\hline \multirow{2}{*}{$\begin{array}{l}\text { Sampling } \\
\text { point }\end{array}$} & Sampling point description & \multicolumn{2}{c}{ Geographical position } \\
\cline { 3 - 4 } & & Latitude & Longitude \\
\hline A & Forest fragment & $\mathrm{N} 358.727$ & E103 14.299 \\
A1 & 300m from forest fragment & $\mathrm{N} 359.048$ & E103 14.440 \\
A2 & 600m from forest fragment & $\mathrm{N} 359.186$ & E103 14.716 \\
A3 & 900m from forest fragment & $\mathrm{N} 358.591$ & E103 14.702 \\
B & Forest fragment & $\mathrm{N} 358.501$ & E103 14.415 \\
B1 & 300m from forest fragment & $\mathrm{N} 358.938$ & E103 14.752 \\
B2 & 600m from forest fragment & $\mathrm{N} 359.014$ & E103 14.828 \\
B3 & 900m from forest fragment & $\mathrm{N} 358.457$ & E103 14.334 \\
C & Forest fragment & $\mathrm{N} 358.451$ & E103 14.509 \\
C1 & 300m from forest fragment & $\mathrm{N} 358.667$ & E103 14.643 \\
C2 & 600m from forest fragment & $\mathrm{N} 358.808$ & E103 14.882 \\
C3 & 900m from forest fragment & $\mathrm{N} 358.375$ & E103 14.289 \\
E & Forest fragment & $\mathrm{N} 358.552$ & E103 14.181 \\
E1 & 300m from forest fragment & $\mathrm{N} 358.592$ & E103 14.056 \\
E2 & 600m from forest fragment & $\mathrm{N} 358.719$ & E103 13.873 \\
E3 & 900m from forest fragment & & \\
\hline
\end{tabular}

\subsection{Data Analysis}

Bird taxonomic data grouped by species, families and orders that was observed in the Bukit Kuantan rubber forest plantation were tabulated using Microsoft Excel according to the distance from SMZ. Several graphs were used in this study to depict the results. To determine the completeness of inventories, species accumulation curve for each distances was plotted using Paleontological Statistics (PAST) Version 2.17, EcoSIM (Null Modelling Software for Ecologist) Version 1 and EstimateS (Statistical Estimation of Species Richness and Shared Species from Samples), while rank abundance curve was constructed using Microsoft Excel. Species accumulation curve also can be used to depict the richness of the sampling points by which the fastest curve that reaches the asymptote reflects the lowest diversity. The rank abundance curve is used to portray relative species abundance within the rubber forest plantation. The rank abundance curve was constructed based on distance from the forest fragment area. The $\mathrm{x}$-axis represents species richness, which can be viewed as the number of different species on the chart. The slope of the curve can be used as a mere indication of species evenness. A steep gradient of the curve designates to low species evenness which indicated the dominant species present in the rubber forest plantation while the less steep gradient of the curve designates to high evenness where the presence of a species is less pronounced. The rank abundance curve is an effective method to illustrate changes through ecological succession or environmental impact. The Venn diagram was constructed to show similarities of bird species that overlapped between sampling points using the bioinformatic tool a vailable at www.bioinformatics.psb.ugent.

The bird diversity captured in the Bukit Kuantan rubber forest plantation was further analysed using several biodiversity indices as listed below using Paleontological Statistics (PAST) Version 2.17. Next, the value obtained from each of the diversity indices (Shannon diversity index, Margalef Diversity Index, Evenness Index, Chao-1 Index ) for each distance $(0 \mathrm{~m}, 300 \mathrm{~m}, 600 \mathrm{~m}, 900 \mathrm{~m})$ were analyze using ANOVA Tukey range test at $\mathrm{p}<0.05$ that performed with Paleontological Statistics (PAST) Version 2.17.

Shannon diversity index is used to determine the species diversity of birds in the Bukit Kuantan rubber forest plantation. The value for species diversity based on Shannon diversity index ranging from $0-4.6$ which the higher value indicates high species diversity. The following equation, the Shannon diversity index, $\mathrm{H}$, is used to calculate the species diversity:

$$
\text { Shanon Diversity Index, } \mathrm{H}=-\sum \mathrm{Pi}(\ln \mathrm{Pi}) ; \mathrm{Pi}=\mathrm{S}
$$

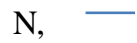

Where $\mathrm{Pi}$ is the proportion of each species in the sample, $\mathrm{S}$ is the number of individuals in one sample and $\mathrm{N}$ is the totalnumber of all individuals in the sample.

The Margalef index is used to measure the species abundance and be able to show the percenta ge of individuals present in an area. Regardless of the number of individuals of a particular species, an addition of one species will affect the Marga lef richness value. The Margalef index value ranges from 0 up to no maximum limit value. As there is no limit value, the index serves for comparison purposes only. The following is the equation for Margalef index: 


$$
\begin{aligned}
\text { Margalef Index, } \mathrm{D}_{\mathrm{m}}= & (\mathrm{S}-1) \\
& \ln \mathrm{N},
\end{aligned}
$$

Where $\mathrm{S}$ is the total number of species while $\mathrm{N}$ is the totalnumber of individuals in the sample.

The Evenness Index measuring the closeness of the number of individuals in one species with other species that present in an area of interest. A community that is dominated by a particular species is considered less diverse compared to a community that has several species present in a similar abundance. Thus, it can be proposed that communities that have an even number of individuals within a particular species are thought to be closer to an equilibrium state and indicates a healthy ecosystem. The value of the Evenness index ranging from 0 to indicate the lowest bird evenness to 1 which indicates high bird evenness. The equation is as follows:

\section{Evenness Index, $\mathrm{E}=\mathrm{H}$}

$\ln \mathrm{S}$,

Where $\mathrm{H}$ is Shannon diversity index whereas $\mathrm{S}$ is the totalnumber of species present in the sample.

\section{Results}

\subsection{Bird Composition}

This study identified a total of 63 species belong to 34 families and 11 orders. The list of identified birds according to their taxonomic rank and feeding guilds can be found in Table 2. The differences between bird orders, families and species across different distances $(0 \mathrm{~m}, 300 \mathrm{~m}, 600 \mathrm{~m}, 900 \mathrm{~m})$ from the forest fragment of SMZ are shown in Figure 1. As for the bird orders, Passeriformes was the most represented order with 35 species. Nonetheless, all distances had almost the same number of orders, ranging from 7 to 9 , with the $900 \mathrm{~m}$ distance having the lowest order which is seven. The area within the forest fragment vicinity recorded the highest number of bird families with 29 families, whereas the distance of $300 \mathrm{~m}, 600 \mathrm{~m}$ and $900 \mathrm{~m}$ from the forest fragment registered similar number of bird families ranging from 20 to 21 families. The number of bird species is higher in the forest fragment with a total record of 45 bird species. Similarly, the number of bird species declined with distance except for the distance of 900 $\mathrm{m}$ recorded 32 bird species, which is higher than 28 bird species recorded at a distance of $600 \mathrm{~m}$, and 36 bird species recorded at a distance of $300 \mathrm{~m}$.

Several common open-country birds such as White-throated Kingfisher (Halycon symrnensis), Yellow-vented Bulbul (Pycnonotus goiaver), Jungle Myna (Acridotheres fuscus) and Oriental-magpie Robin (Copsychus saularis) showed an obvious reduction in terms of abundance across the distance within the forest fragment. Records also indicate that in this research, there are several species that were found only once in this study. The single register comprise of Common Kingfisher (Alcedon atthis), Large-tailed Nightjar (Caprimulgus macrurus), Slender-billed Crow (Corvus enca), Red-billed Malkoha (Phaenicophaeus javanicus), Black-thighed Falconet (Microhierax fringillarius), White-rumped Munia (Lonchura striata), Long-tailed Shrike (Lanius schach), Blue-throated Bee-ea ter (Merops viridis), Ferruginous Flycatcher(Muscicapa ferruginea), Ruby-cheeked Sunbird (Chalcoparia singalensis), Grey-breasted Spider-hunter (Arachnothera modesta), Grey-capped Woodpecker (Dendrocopos canicapillus), Rufous Woodpecker (Celeus brachyurus), Crimson-winged Woodpecker (Picus puniceus), Black-headed Bulbul (Pycnonotus atriceps), Stripe-throated Bulbul (Pycnonotus finlaysoni), White-throated Fantailed (Rhipidura albicolis) and Barred Buttonquail(Turnix suscitator). 


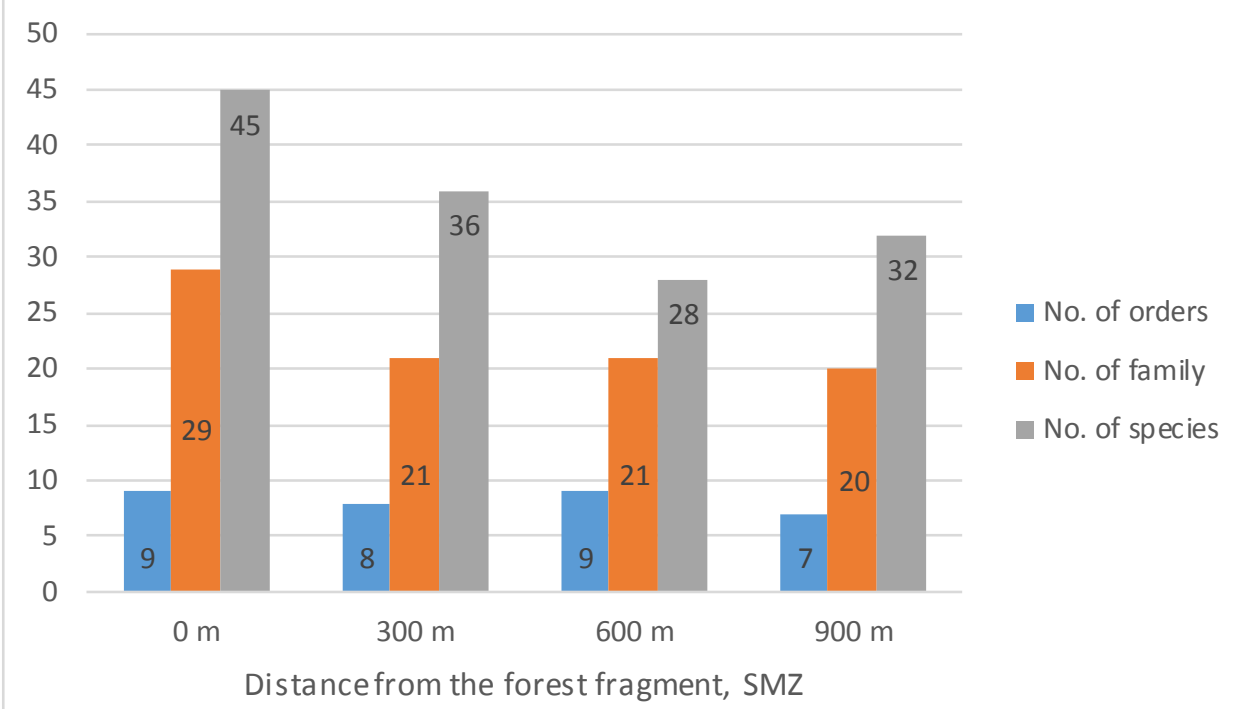

Fig. 1. Number of bird orders, families and species according to the distance from the forest fragment 


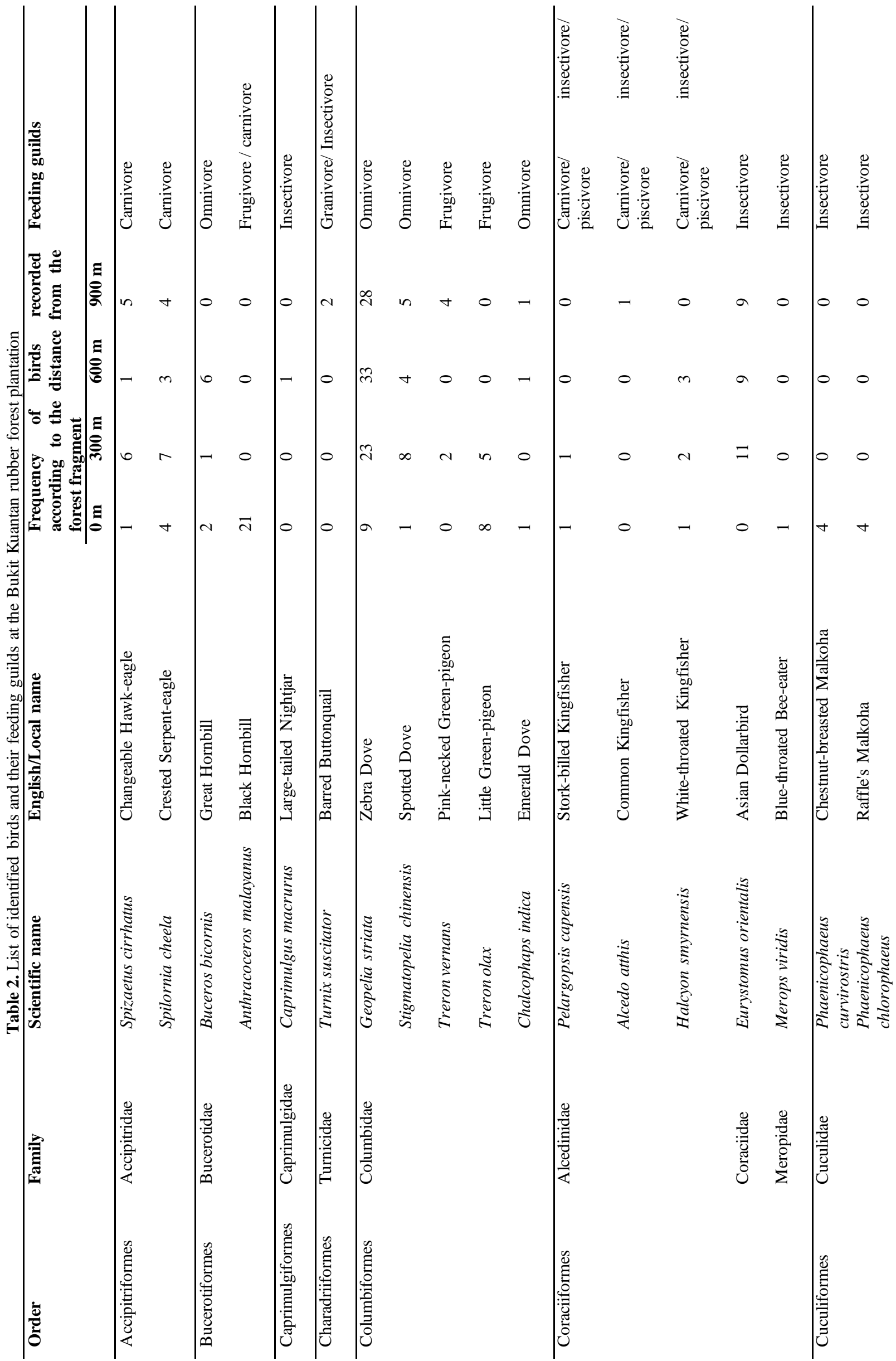




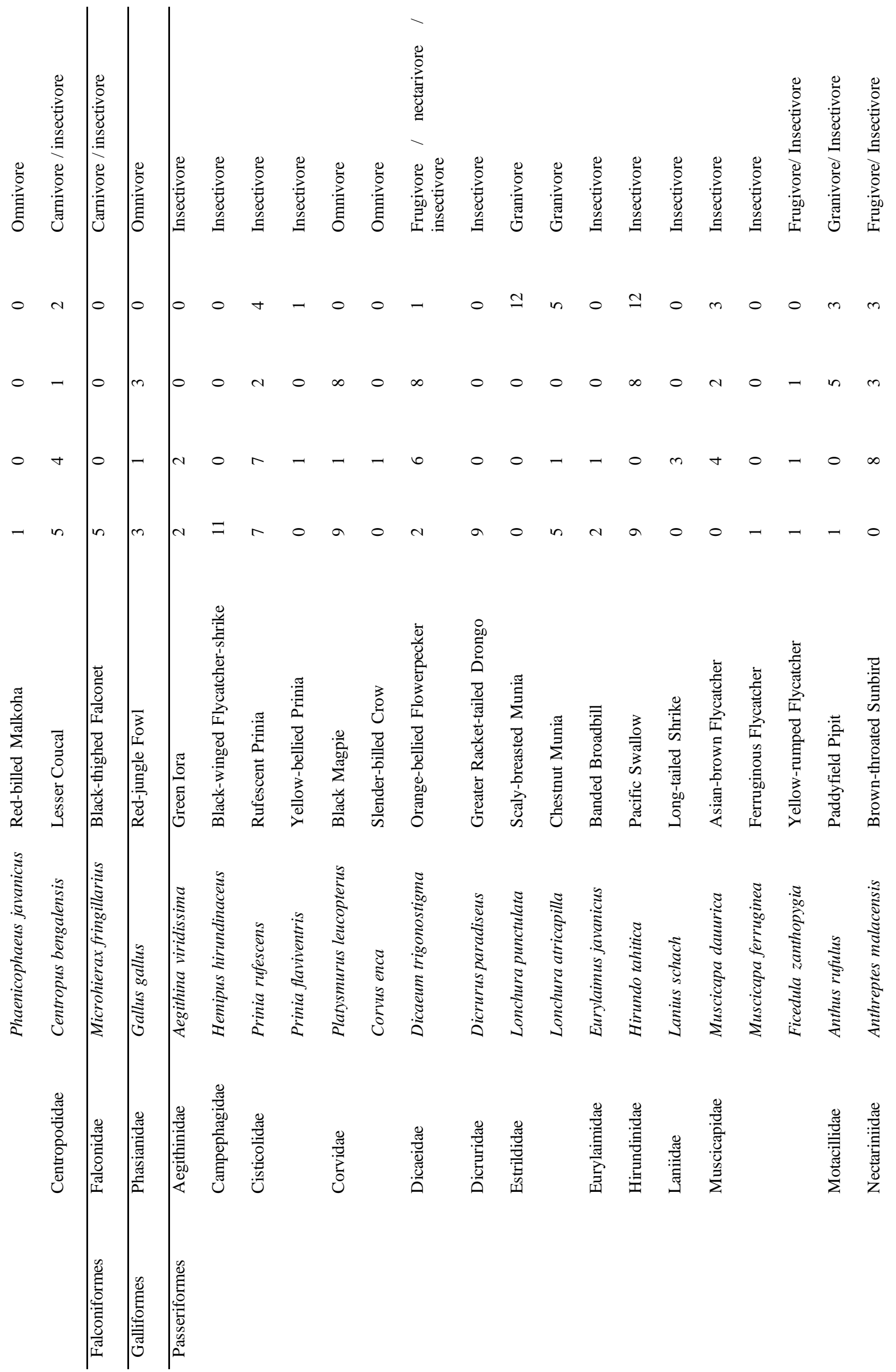




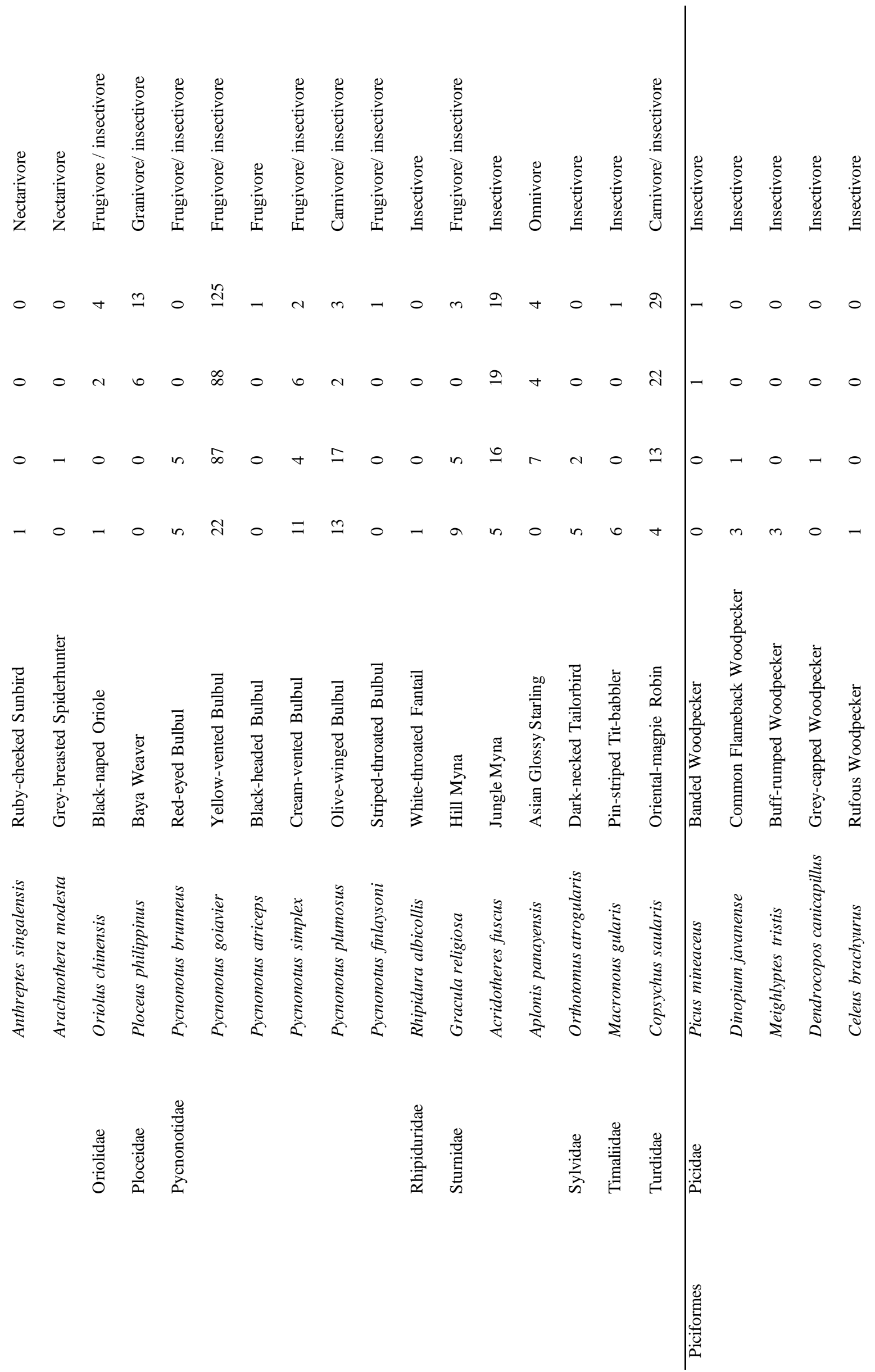




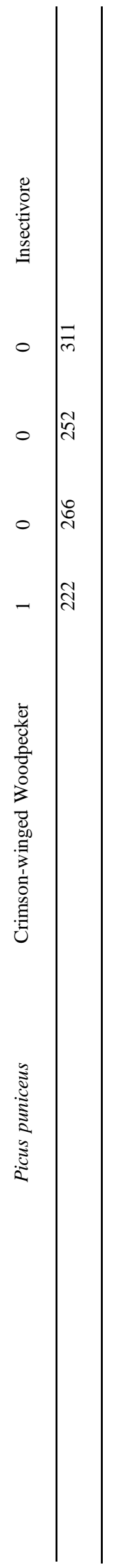




\subsection{Bird Feeding Guilds}

In this study, birds were categorized into six major feeding guilds as shown in Figure 2. Several studies have categorized bird feeding guilds into very specific categories, particularly for the insectivore-complex feeding guild (Nur Munira et al. 2011; Li et al. 2013). However, for this study, the complex feeding guilds (i.e., frugivorenectarivore-insectivore, frugivore-carnivore; granivore/ insectivore etc.) are simply referred to as omnivore, which feeds both plant parts and other animals (Achondo et al. 2011). The Bukit Kuantan rubber forest plantation was dominated by omnivorous birds followed by insectivorous birds. The rest of the feeding guilds, which are frugivore, granivore, nectarivore, and carnivore, were slightly similar, with two to three bird species recorded.

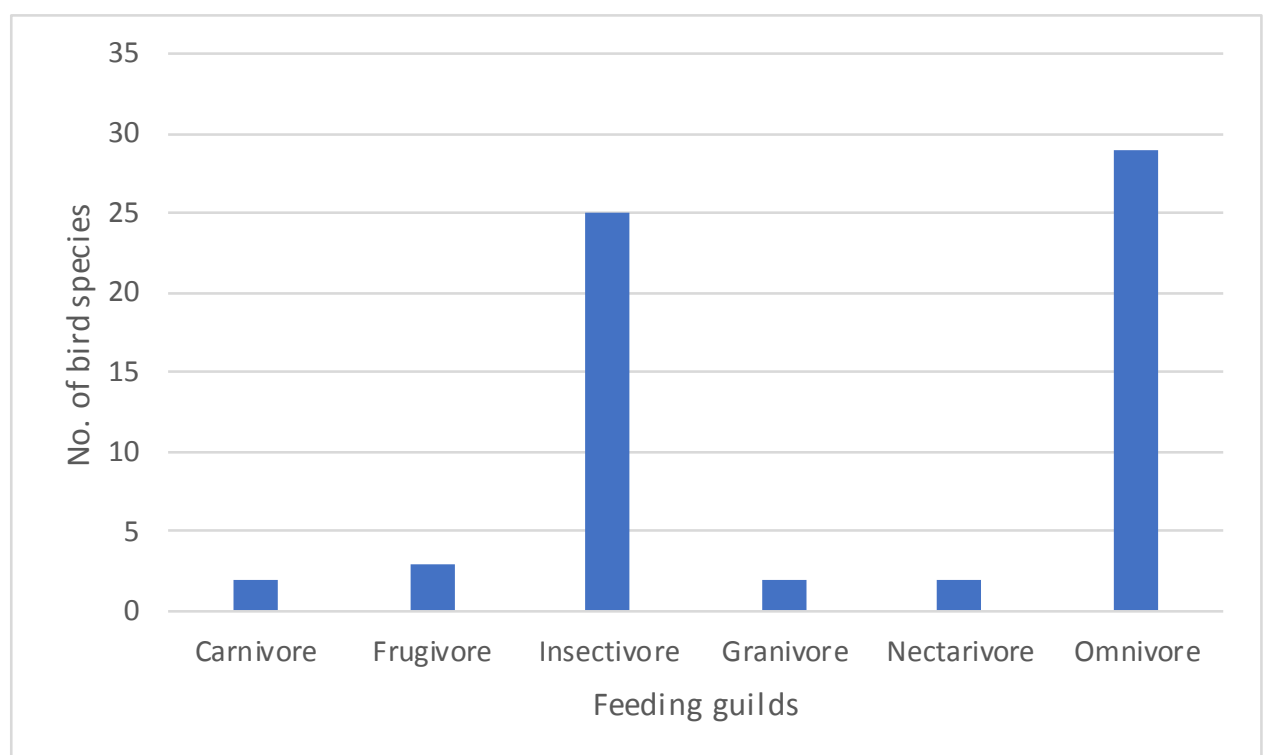

Fig. 2 Feeding guilds composition based on the number of bird species recorded in the Bukit Kuantan rubber forest plantation

\subsection{Rank Abundance Curve}

Fig. 3 shows the rank abundance curve that was established for the Bukit Kuantan rubber forest plantation. Interestingly, for each sampling distance, it was found that Yellow-vented Bulbul managed to rank first, which is an indication of its high abundance in the Bukit Kuantan rubber forest plantation. The plotted curve was steeper for distances of $300 \mathrm{~m}, 600 \mathrm{~m}$ and $900 \mathrm{~m}$ from the forest fragment, while it was gentler for distances of $0 \mathrm{~m}$ from the forest fragment, which also had a higher number of species. A steep slope may indicate low evenness as the first rank species have higher abundance than the subsequent species, while a gentler slope may indicate high evenness as the abundance of different species are similar. 


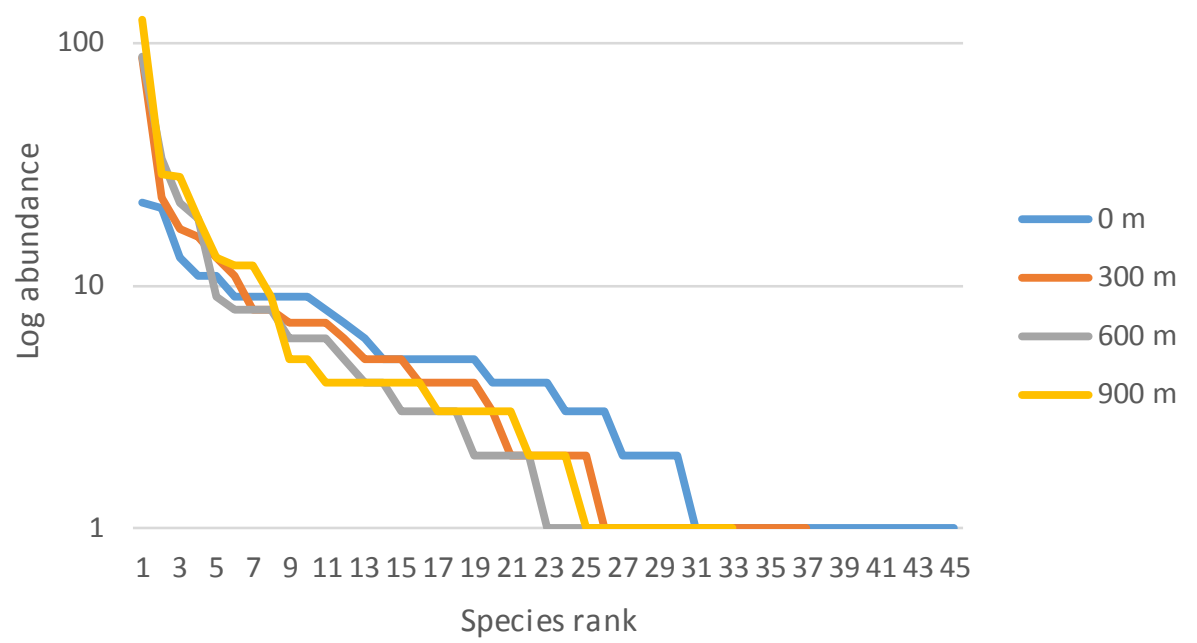

Fig. 3 Rank abundance curve of birds in the Bukit Kuantan rubber forest plantation according to the distance from the forest fragment

\subsection{Species Accumulation Curve}

To indicate the adequateness of the sampling effort, the species accumulation rates were done and depicted in Fig. 4 by the species accumulation curve of birds. Further, the curve shows the changes in the number of species accumulated as the number of observed species were added. From the curve, it can also be deduced that sampling efforts in forest fragment $(0 \mathrm{~m})$ appeared somewhat inadequate, which indicates the potential of finding new species with more sampling effort.

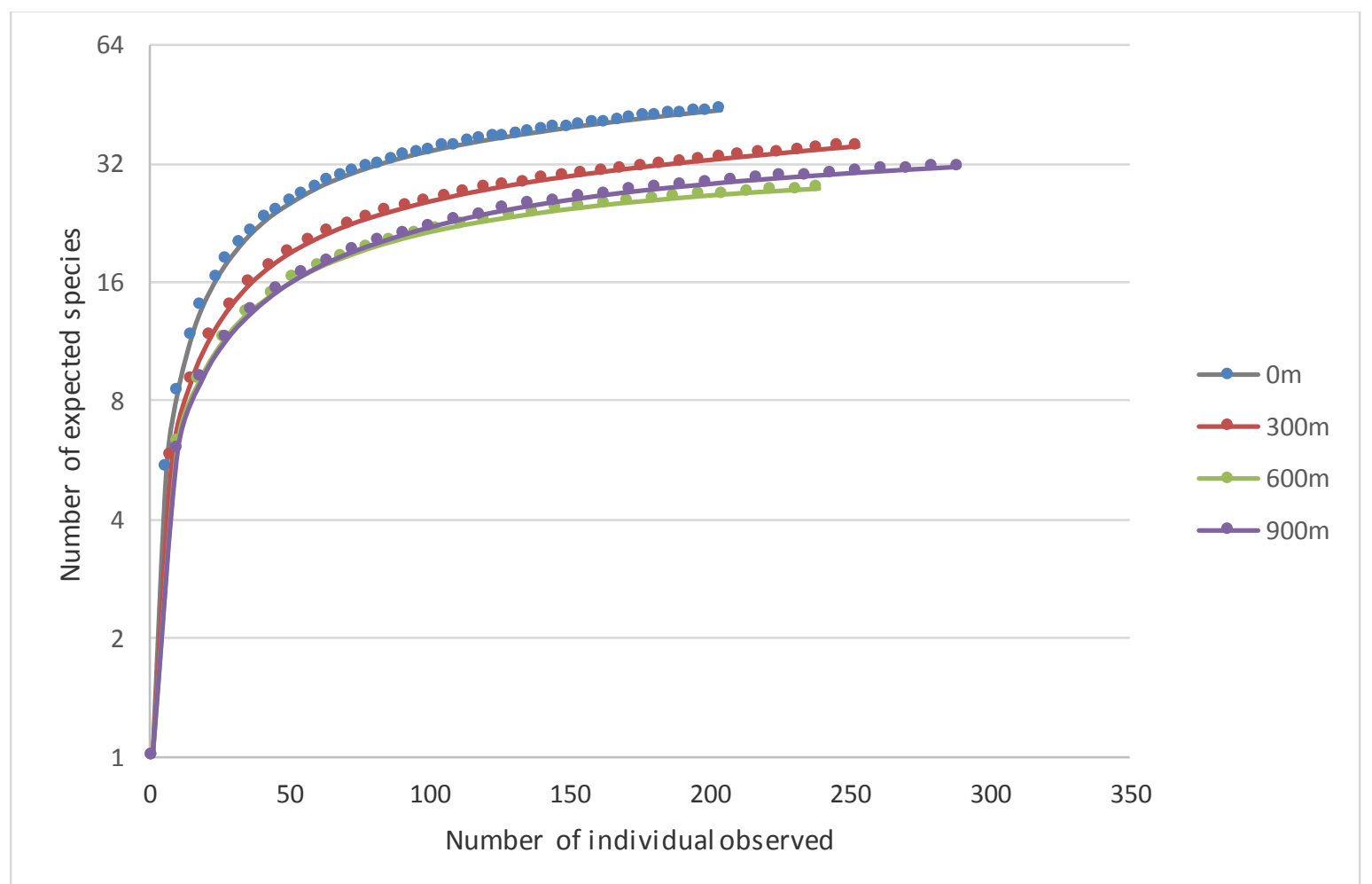

Fig. 4 Species accumulation curve of birds in the Bukit Kuantan rubber forest plantation according to the distance from the forest fragment 


\subsection{Venn Diagram}

A Venn diagram was constructed to give an overview of the distribution of bird species across the distance from the forest fragment. Fig. 5 shows the Venn diagram of the shared species occupied different distance from the forest fragment (i.e., $0 \mathrm{~m}$ distance indicate forest fragment, $300 \mathrm{~m}$ from forest fragment, $600 \mathrm{~m}$ from forest fragment and $900 \mathrm{~m}$ from forest fragment). Based on the figure, the forest fragment ( $0 \mathrm{~m}$ distance $)$ was the exclusive areas where 14 bird species were recorded. The bird species were Black Hornbill (Anthracocerus malayanus), Black-winged Flycatcher Shrike (Hemipus hirundinaceus), Chestnut-breasted Malkoha (Phaenicophaeus curvirostris), Red-billed Malkoha (P. javanicus), Raffle's Malkoha (Phaenicophaeus cholorophaea), Greater Racket-tailed Drongo (Dicrurus paradiseus), Blue-throated Bee-eater(M. viridis), Ferruginous Flycatcher(M. ferruginea), Ruby-cheeked Sunbird (C. singalensis), Buff-rumped Woodpecker (Meighlyptes grammithorax), Rufous Woodpecker ( $C$. brachyurus), Crimson-winged Woodpecker (P. puniceus), Black-thighed Falconet (M. fringillarius) and Whitethroated Fantailed (R. albicolis).

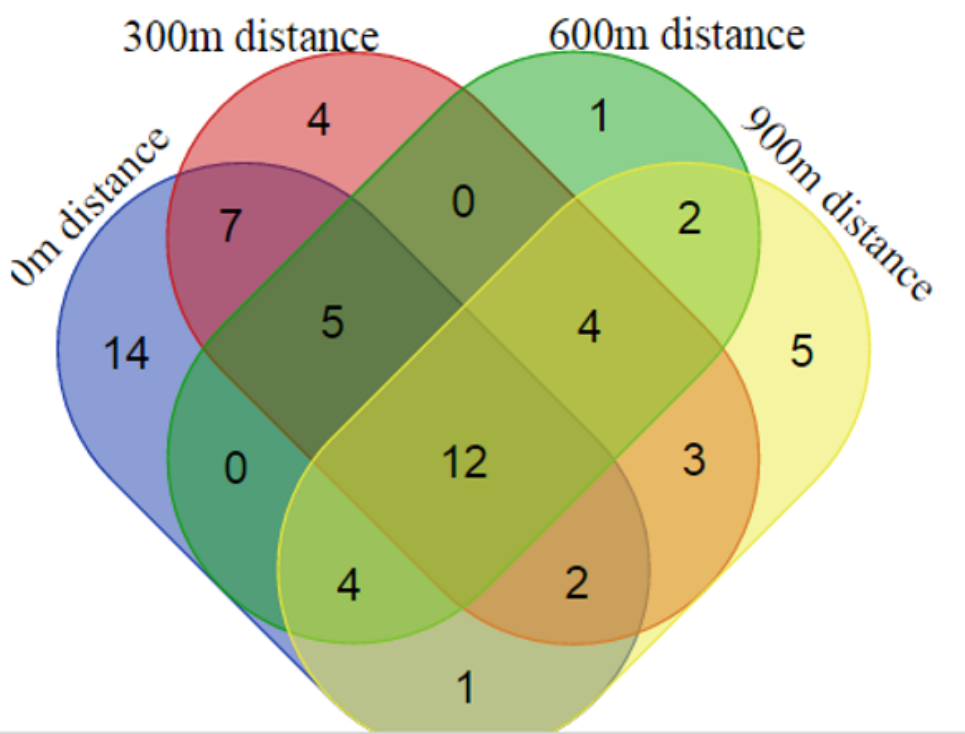

Fig. 5 Venn diagram of bird's assemblages between distance of forest fragment and rubber area

\subsection{Bird Diversity Indices}

There are several methods a vailable for estimating species diversity, and to identify and characterize species that are present in a particular habitat or region. Table 3 shows the species diversity of bird population within four separate distances of the Bukit Kuantan rubberforest plantation.

The Shannon diversity index takes into account the species richness (i.e., number of species) and species evenness (i.e., uniformity of species) into its value. Shannon diversity index value ranged from 1.5 to 3.5 but rarely exceeds 4.0. From these values, it can be deduced that the diversity value declined when the sampling points receded further from the forest fragment. The highest value for bird diversity was 3.404 at the forest fragment $(0 \mathrm{~m})$, and the lowest value was 2.410 at the furthest distance from the forest fragment $(900 \mathrm{~m})$. Nonetheless, in terms of analysis, there was no significant difference between distances as determined by one-way ANOVA $\left(\mathrm{F}_{3,12}=1.481, \mathrm{P}=0.269\right)$.

Evenness index is the measure of the relative abundance of the different species that make up the richness of an area. In this study, the bird evenness value was the highest at the forest fragment $(0 \mathrm{~m})$ with a value of 0.668 and lowest at the distance farthest from the forest fragment $(900 \mathrm{~m})$ with a value of 0.348 . Similar to the Shannon diversity index, this a nalysis showed no significant difference between distances as determined by one-way ANOVA $(\mathrm{F} 3,12=1.606, \mathrm{P}=0.240)$.

Margalef richness index is an index weighted towards species richness (number of species), in which the more species present in an area, the richer the richness value. Thus, it is not surprising that from the four diversity indices used in this study, only the Margalef index gave a higher value for the distance of $900 \mathrm{~m}(5.401)$ than the distance of $600 \mathrm{~m}$ (4.883) as more species were obtained at the distance of $900 \mathrm{~m}$ compared to the distance of $600 \mathrm{~m}$. In tems of a nalysis, there was no significant difference between distances as determined by one-way ANOVA (F3,12=2.476, $\mathrm{P}=0.111)$. 
Chao-1 is the only nonparametric estimator used in this study to provide a minimum estimation of species richness in an area. All estimations were higher than the observed value. Likewise, the trend of the Ch a o- 1 estima tor also indicates that the area within forest fragment, ie SMZ has the highest estimated species followed by $300 \mathrm{~m}, 900$ $\mathrm{m}$ and $600 \mathrm{~m}$ distance from the forest fragment.

Table 3. Bird species diversity at Bukit Kuantan rubber forest plantation according to the distance from the forest fragment

\begin{tabular}{lllll}
\hline Parameters & Values & & & \\
\cline { 2 - 5 } & $0 \mathrm{~m}$ (forest fragmet) & $\begin{array}{l}300 \mathrm{~m} \text { distance from } \\
\text { the forest fragment }\end{array}$ & $\begin{array}{l}600 \mathrm{~m} \text { distance from } \\
\text { the forest fragment }\end{array}$ & $\begin{array}{l}900 \mathrm{~m} \text { distance from } \\
\text { the forest fragment }\end{array}$ \\
\hline $\begin{array}{l}\text { Taxa, (Species) } \\
\text { Shannon diversity } \\
\text { index }\end{array}$ & 45 & 36 & 28 & 32 \\
Evenness index & 3.404 & 2.733 & 2.461 & 2.410 \\
Margalef index & 0.668 & 0.427 & 0.419 & 0.348 \\
Chao-1 index & 8.144 & 6.268 & 4.883 & 5.401 \\
\hline
\end{tabular}

\section{Discussion}

The high value of bird species recorded in the forest fragment might implicates on the impact and importance of forest fragment area for conserving bird diversity. Similar results were also obtained by other researchers such as in Azlan et al. 2019; de Matos et al. 2018; Zhanget al. 2017; Guerra et al. 2012; Aratrakorn et al. 2006; Marsden et al. 2001). Species such as Cream-vented Bulbul(Pynonotus simplex) showed an obvious reduction in term of abundance when far from the forest fragment while species such as Yellow-vented Bulbul ( $P$. goiaver) and Oriental-magpie Robin (C. saularis) showed an obvious increment in the term of abundance when far from the forest fragment. This result was due to the sensitivity of the bird species by which the colonizer and ge neralist species preferred open habitat compared to the forest fragment area. Studies elsewhere have shown that birds such as Bulbuls (Pycnonotidae) are known to strive well in a disturbed and modified environment (Ramli et al. 2009). Likewise, a similar result was also reported by Azlan et al. (2019) who found that the forest bird species decreased with the distance from the forest edge into oil palm plantation.

The preservation of forest fragments within the plantation can be proposed as an option that can be taken by plantation management in enhancing biodiversity. Peh et al. (2006) in their study also emphasized that the high number of bird species recorded in their study might be due to the presence of nearby forests. Bird diversity is also influenced by the availability of food sources. The Bukit Kuantan rubber forest plantation was dominated by omnivorous birds. To continue their existence in limited food sources, some bird species have adapted to this situation by being an omnivore and switch their diet based on the a vailable food sources at that time (Nur Munira et al. 2011). Insectivorous birds are the second most common feeding guilds, and this is supported by a study carried out by Achondo et al. (2011) which also found that insectivorous birds a re common in a commercialplantation. On the other hand, Sheldon et al. (2010) and Li et al. (2013) proposed that insectivore birds in plantations are reduced compared to the secondary forest due to the land clearing and agricultural practices. According to Perfecto et al. (2004), a high abundance of insectivorous birds such as Oriental-magpie Robin (C. saularis) and Yellow-vented Bulbul ( $\mathrm{P}$. goiavier) has several advantages, including helping to stabilize insect populations and preventing pest outbreaks.

The optimistic outcome of preserving the forest fragment was further proved by the 14 bird species or circa. $20 \%$ of the total number of species that can only be observed only in the forest fragment. Forest fragment within plantations have been shown to play a significant factor in conserving bird diversity as diminishing species such as Crested-serpent Eagle (Spilornia cheela), Black Hornbill (A. malayanus) and Great hornbill (Buceros bicarnus) were detectable at the farthest distance from forest fra gment (Datta, 1998; Ueta and Minton, 1996). In addition, a vailable preserved forest fragment has been shown to aid and enhance bird diversity by providing a transition area in which birds migrated daily from the forested area to the near plantation area (Mitra and Sheldon, 1993). The presence of the fa mily Bucerotidae (Hornbill) and Picidae (Woodpecker) which are sensitive to habitat change adds further proof to the importance of forest fragment (Ayat,2011). Teusher et al. (2015) reported that disparities in tree diversity and height of ground cover vegetation gave a positive effect on bird diversity. Besides that, retaining some of the old trees and increasing the inter-tree planting distance in rubber plantations allow some understory vegetation to coexist also were some of the approaches that could increase the bird diversity (Zhang et al. 2017).

Although there is much speculation on the practicalvalue of the indices, based on Magurran,(2004) the Shannon index works best when used to compare diversity between areas. The Shannon index showed a declining pattem although the distance of $900 \mathrm{~m}$ recorded a higher number of species than the distance of $600 \mathrm{~m}$. This due to the index 
formula which considered the richness and evenness of the species. Thus, although the $900 \mathrm{~m}$ distance showed a higher number of species, in term of species diversity, it registered the lowest bird diversity.

For the evenness index, the presence of Yellow-vented Bulbul (P. goiaver) in a high abundance at the distance of $900 \mathrm{~m}$ was probably the major factor in the low evenness value. According to Ramli et al. (2009), species richness as indicated by Margalef Index is one of the simplest ways in describing the diversity value within the community and regional stage. The possible explanation of high bird richness at the distance of $900 \mathrm{~m}$ might be due to the multiple microhabitats at the distance of $900 \mathrm{~m}$ which comprises the rubber tree, secondary forest, wetland area, building and road that attract different species that occupied the different niche.

Though not statistically significant, the trend of diversity generally decreased in this study when the point of observation moves further a way from the forest fragment, in a greement with the earlier reports of Azlan et al. (2019), Aratrakorn et al. (2006) and Marsden et al. (2001). Elsewhere, forest cover has been proposed to have a bearing on bird diversity (Sreekar et al. 2016). While the population may have very similar indices of diversity in terms of richness and evenness, the probability of the community having different species should not be ignored (Magurran 2004). The evaluation of bird taxonomy revealed that the forest fragment harbour different bird species such as forest edge bird species that can tolerate slight disturbance to continue their adaptability in a rubber forest plantation. Thus, although no quantitative outcome could be derived from this study, in terms of quality, it showed optimistic results pertaining to bird diversity.

\section{Conclusion}

Through certain approaches and strategies, plantation s can be fostered into an area that is favourable to biodiversity. Studies have shown that the presence of forested areas in plantations area is able to increase bird richness and abundance. Further work should focus on determining the resiliency of the birds to continue their existence in the same landscape. By providing a plantation ground that is suitable for biodiversity conservation, rubber forest plantation management system can be tweaked to beneficial for both the economy and the environment.

\section{References}

1. Achondo, M.J.M.M., Casim, L.F., Bello, V.P., Tanalgo, K.C., Agduma, A.R., Bretana, B.L., Mancao, L.S., Salem, J.G.S. \& Supremo, J.P. 2011. Rapid assessment and feeding guilds of birds in selected rubber and oil palm plantations in North Cotabato. Asian Journal of Biodiversity. 2: 103-119.

2. Aratrakorn, S., Thunhikorn, S. and Donald, P.F. 2006. Changes in bird communities following conversion of lowland forest to oil palm and rubber plantations in southern Thailand. Bird Conservation International 16: 7182.

3. Ayat, A. 2011. Bird diversity in rubber plantations and their surroundings. Recognizing biodiversity in rubber plantation (ed:Tata, E.D.) Bagor, Indonesia: World Agroforestry Centre (ICRAF) Southeast Asia Regional Program.

4. Aziz, S.A., Laurance, W.F. and Clements, R. 2010. Forests reserved for rubber. Frontiers in Ecology and the Environment. Doi:10.1890/10.WB.014.

5. Azlan M.J., Fang, V.A.M., Kaicheen, S.S., Lok, L. and Lawes, M.J. 2019. The diversity of understoey birds in forest fragment and oil palm plantation, Sarawak, Borneo. Journal of Oil Palm Research 31: 437-447

6. Behm, J.E., Yang, X. \& Chen, J. 2013. Slipping through the cracks: rubber plantation is unsuitable breeding habitat forfrogs in Xishuangbanna, China. Plos One 8(9): 1-13.

7. Bibby, C.J., Burgess, N.D. and Hill D.A. 1992. Bird census techniques. Academic Press, London. 302 pp.

8. Blakewell, D. 2012. Checklist of the Birds of Peninsular Malaysia. Malaysian Nature Society - Bird Conservation Council Records Committee [1 May 2016].

9. Chacoff, N.P. \& Aizen, M.A. 2006. Edge effects on flower-visiting insects in grapefruit plantation bordering premontane subtropical forest. Journal of Applied Ecology 43:18-27.

10. Cotter, M., Martin, K. \& Sauerborn, J. 2009. How do "renewable products" impact biodiversity and ecosystem services - the example of natural rubber in China Journal of Agriculture and Rural Development in the Tropics and Subtropics 110(1): 9-22.

11. Datta, A. 1998. Hornbill abundance in unlogged forest, selectively logged forest and a forest plantation in ArunachaiPraddesh, India. Oryx. 32(4): 285-294.

12. Davison, G. W. H. \& Aik, Y. C. 2010. A naturalist's guide to the birds of Malaysia and Singapore: including Sabah \& Sarawaknaturalist guide. Oxford, United Kingdom: John Beaufoy Publishing.

13. Davison, G. W. H. \& Fook, C. Y. 2003. A photographic guide to birds of peninsular Malaysia and Singapore. London, United Kingdom: New Holland. 
14. de Matos, V.P.V., de Matos, T.P.V., Cetra, M., e Timo, T.P.D.C. \& Velente, R.A. 2018. Forest fragmentation and impacts on the bird community. Revista Arvore 42(3): e420309.

15. Dumbrell, A.J., Clark, E.J., Frost, G.A., Randell, T.E., Pitchford, J.K. \& Hill, J.K. 2008. Changes in species diversity following habitat disturbance are dependent on spatial scale: theoretical and empirical evidence. Journal of Applied Ecology 45: 1531-1539.

16. Guerra, B.R., Renton, K. \& Dirzo, R. 2012. Consequences of fragmentation of tropical moist forest forbirds and their role in predation of herbivores insects. Biotropica 44(2): 228-236.

17. Ismail, A. \& Syaizwan, Z.Z. 2005. Bird survey in vegetated area around Kuala Lumpur International Airport Sepang, Selangor. Malaysian Applied Biology 34(1): 53-57.

18. Jamil, N.H.M., Ismail, A., Zulkifli, S.Z. \& Rahman, F. 2015. Population size and density of Southern Pied Hornbill (Anthracoceros albirostris convexus) in human settlement area in vicinity of Sungai Karang Forest Reserve, Malaysia.Acta Biologica Malaysiana.4(1): 26-31.

19. Li, S., Zou, F., Zhang, Q. and Sheldon, F.H. 2013. Species richness and guild composition in rubber plantations compared to secondary forest on Hainan Island, China. Agroforestry Systems 87: 1117-1128.

20. Magurran, A.E. 2004. Mea suring biological diversity. Blackwell Publishing.

21. Marsden.S.J., Whiffin, M. \& Galetti, M. 2001. Bird diversity and abundance in forest fragment and Eucalyptus plantations around Atlantic forest reserve, Brazil. Biodiversity and Conservation 10: 737-751.

22. Mitra, S.S. \& Sheldon, F.H. 1993. Use of an exotic tree plantation by Borneo lowland forest birds. The Auk. 110(3): $529-540$

23. Murcia, C. 1995. Edge effects in fragmented forests: implications for conservation. Tree 10(2): 58-62.

24. Najera, A. \& Simonetti, J.A. 2009. Enhancing a vifauna in commercial plantations Conservation Biology 24(1): 319-324.

25. Najera, A. \& Simonetti, J.A. 2010. Can oil palm plantations become bird friendly? Agroforestry System 80: 203-209.

26. Norton, D.A. 1998. Indigenous biodiversity conservation and plantation forestry: options for the future. New Zealand Forestry 43(2): 34-39

27. Nur Munira, A., Nurul Salmi, A. L., Shahrul Anuar, M. S., Mohd Abdul Muin, M. A., Nur Juliani, S., \& Nurul Liyana, K. 2011. Avian Diversity and Feeding Guilds in a Secondary Forest, an Oil Palm Plantation and a Paddy Field in Riparian Areas of the Kerian River Basin, Perak, Malaysia. Tropical Life Sciences Research 22(2): 45-64.

28. Peh, K.S.H., Sodhi, N.S., de Jong, J., Sekercioglu, C.H., Yap, C.A.M. \& Lim, S.L.H. 2006. Conservation value of degraded habitats for forest birds in southern Peninsular Malaysia. Diversity and Distributions. 12(5): 572-581.

29. Perfecto, I., Vandermeer, J.H., Bautista, G.L., Nunez, G.I., Greenberg, R., Bichier, P. \& Langridge, S. 2004. Greater predation in shaded coffee farms: the role of resides neotropicalbirds. Ecology 85(10): 2677-2681.

30. Ralph, C. J., Droege, S. \& Sauer, J. R. (1995). Managing and monitoring birds using point counts: standards and applications. In C. J. Ralph, J. R. Sauer \& S. Droege (Eds.), Monitoring bird populations by point counts (pp. 161-168). Albany, CA: Department of Agriculture, Forest Service, Pacific Southwest Research Sta tion.

31. Ramli, R., Ya'cob, Z. \& Hashim, R. 2009. Diversity of birds in Kenaboi Forest Reserve, Jelebu, Negeri Sembilan Malaysia. Malaysian Journal of Science 28(4): 465-480.

32. Sheldon, F.H. Styring, A. \& Hosner, P.A. 2010. Bird species richness in a Bornean exotic tree plantation: A long-term perspective. Biological Conservation 143: 390-407.

33. Sreekar, R., Huang, G., Yasuda, M., Quan, R.C., Goodale, E., Corlett, R.T. \& Tomlinson, K.W. 206. Effects of forests, roads and mistletoe on bird diversity in monoculture rubber plantation. Scientific Reports 6: 21822. https://doi.org/10.1038/srep21822

34. Ueta, M. \& Minton, J.S. Habitat preference of Crested-serpent Eagles in southern Japan. Journal of Raptor Research 30(2): 99-100.

35. Warren-Thomas, E., Dolman, P.M. \& Edwards, D.P. 2015. Increasing demand for natural rubber necessitates a robust sustainability initiative to mitigate impacts on tropical biodiversity. Conservation Letters 8(4): 230241 .

36. Wielstra, B., Boorsma, T., Pieterse, S.M. \& de Iongh, H.H. 2011. The use of a vian feeding guilds to detect small-scale forest disturbance: a case study in East Kalimantan, Borneo. Forktail 27: 55-62.

37. Wong, T. S. 2012. A Natura list's Guide to the Birds of Borneo. England: John Beaufoy Publishing.

38. Zhang, M., Chang, C. \& Quan, R. 2017. Naturalforest at landscape scale is most important for bird conservation in rubber plantation. Biological conservation 210: 243-252. 